\title{
Anonymous Women? A Scoping Review of the Experiences of Women in Gamblers Anonymous (GA)
}

\author{
Jim Rogers ${ }^{1}$ (D) Jason Landon ${ }^{2} \cdot$ Stephen Sharman $^{3} \cdot$ Amanda Roberts $^{4}$ \\ Published online: 18 June 2019 \\ (C) The Author(s) 2019
}

\begin{abstract}
Women are participating in gambling at levels approaching those of men, and although levels of disordered gambling remain lower in women than in men, significant numbers are affected. Gamblers Anonymous (GA) is a mainstay of help to problem gamblers in many countries. A scoping review was conducted which specifically addressed the experiences of women who attend GA. Within the 25 identified relevant studies, only two reported empirical data on the specific numbers of women attending. A range of barriers still remain to the participation of women in these communities. These include 'external' barriers such as lack of referral and signposting, lack of accessible meetings, and costs of travel; 'internal' barriers such as shame, stigma, and fear of disclosure; and features of the GA meetings and discourse, such as a climate which is dismissive of women's experiences.
\end{abstract}

Keywords Gamblers Anonymous · Women · Gender · Disordered gambling · Barriers to participation

\section{Background}

Gambling has traditionally been a socially acceptable behaviour among men (Potenza et al. 2001; Svensson and Romild 2014). In recent years, gambling environments have changed, making a large range of gambling opportunities more physically and socially accessible than

Jim Rogers

jrogers@lincoln.ac.uk

Jason Landon

jason.landon@aut.ac.nz

Stephen Sharman

ssharman@uel.ac.uk

Amanda Roberts

aroberts@lincoln.ac.uk

Extended author information available on the last page of the article 
ever before, especially through the internet and the increasing uptake of mobile technologies (Griffiths 1999; Gambling Commission 2018). With a worldwide liberalisation of gambling legislation, changing gender roles, and greater economic resources available to many women, some of the traditional barriers to the participation of women in many gambling activities have been removed (Bowden-Jones and Prever 2017). Hence, the participation of women in gambling activities has steadily increased in recent decades (Abbott et al. 2014; Afifi et al. 2010; Crisp et al. 2004; Wardle and Seabury 2013).

The rapid change in the variety and reach of gambling products has been paralleled by changes in harm at a population level. Some studies indicate that both the overall number and the proportion of 'problem gamblers' who are women has also increased (Wardle et al. 2011; Conolly et al. 2018). There remains a lack of consensus about exactly what constitutes problematic gambling and a range of definitions and measures have been proposed to assist in elucidating and calculating the size and scale of the problems which can be associated with gambling, whether for the individual, their family, or the wider society. The range of terms includes 'problem', 'pathological', 'disordered', 'compulsive', 'excessive', and 'at risk' (Griffiths 2014). The currently favoured term across much of the field of gambling studies is to use 'disordered gambling' since this is the nomenclature adopted in the most recent version of the Diagnostic Manual of Mental Disorders (American Psychiatric Association 2013). For consistency, the term 'disordered gambling' will be therefore used through the remainder of this paper, unless other terms are used in the paper being reviewed.

Evidence indicates that self or mutual help groups such as Alcoholics Anonymous (AA) and Gamblers Anonymous (GA), which offer 'twelve-step' programmes, are effective for many of those in recovery from addiction (Kelly 2017; Parkman, Lloyd, and Spilsbury 2015). Twelve-step programmes remain dominant in the addiction treatment landscape, particularly in North America (Ferentzy et al. 2004; Schuler et al. 2016) providing much of the help available to people trying to recover from addictions of all of kinds, including substance abuse problems, and behavioural addictions such as gambling. GA remains the most widely available source of face-to-face help for many with gambling disorders worldwide (Viets and Miller 1997; Rogers 2018). With over 150 GA weekly meetings across the UK, GA provides a major source of face-to-face help and is considered by many as one of the main avenues of support for many disordered gamblers seeking help and treatment (Abbott et al. 2004; Rogers 2018). Worldwide, GA groups vary according to country; in the USA, there are over 1000 GA groups, and the GA approach is integrated into many other disordered gambling treatment programmes (Petry and Steinberg 2005), Australia has over 130 GA groups, Japan over 120, and rates vary across European countries with just two listed in Norway and 97 listed for Italy (Gamblers Anonymous 2017).

As increasing numbers of women are reporting gambling disorders and since one of the most widely available form of help is GA, it would be beneficial to know more about the experiences of women who attend. Furthermore, it would be helpful to explore issues of gender in relation to the structure and operation of the meetings. The programmes offered by GA are based on mutual and self-help, with a strong focus on anonymity; hence, information about participants is often difficult to obtain. A review in 2003 concluded that 'GA remains a black box about which we know too little' (Ferentzy and Skinner 2003, p16). Research on these programmes remains limited; many of the meetings are 'closed' and do not permit researchers or non-disordered gamblers to attend. Hence, a review of previous literature on GA and an understanding of what is offered to women is essential. 
A recent scoping review of GA focussed on GA in North America (Schuler et al. 2016), therefore did not include studies of GA in Great Britain and elsewhere. Moreover, although the authors did make reference to issues of gender and suggest that their review provided 'preliminary evidence of the status of women in the fellowship' (Schuler et al. 2016, p1275), they only briefly noted specific findings related to women in five of their included studies. Other reviews of GA are now somewhat dated (Ferentzy and Skinner 2003), and Schuler et al. (2016) in their review noted the need for further studies to generate knowledge about gender composition at GA. To address this knowledge gap, we conducted a specific scoping review of all available literature on GA documenting the experiences of women, and included studies from all parts of the world. A scoping review was chosen as this approach is considered to be the best method for mapping literature, summarising findings and exploring the extent to which a particular area has been researched (Arksey and O'malley 2005).

Our goal was to inform the research and treatment communities of GA practices regarding women's experiences of GA. The primary objectives of the review were to determine levels of participation of women in GA, and to determine key barriers and facilitators to the participation.

To do this, we set out to review the available literature on GA, with a specific focus on those studies which made any reference to women.

\section{Methods}

Guidelines for Scoping Reviews produced by The Centre for Reviews and Dissemination (CRD 2001) were followed to ensure rigour and comprehensive coverage. To identify relevant studies, a three-stage approach was taken, with two reviewers independently searching for and checking studies against a pre agreed protocol, and against predefined inclusion and exclusion criteria which are detailed in Table 1.

\section{Identifying Relevant Studies}

The following databases were searched for eligible studies up to and including 2018 Medline, PsycINFO, EMBASE (Excerpta Medica Database), CINAHL plus, and Web of Knowledge. After the initial database search, duplicates were removed. The total number of articles located from these searches was 186 .

Table 1 Inclusion and exclusion criteria for the literature review

\begin{tabular}{|c|c|}
\hline Inclusion criteria & Exclusion criteria \\
\hline $\begin{array}{l}\text { Study type: quantitative or qualitative studies that } \\
\text { explore involvement with Gamblers Anonymous of } \\
\text { people facing gambling disorders. Any study design } \\
\text { was included. }\end{array}$ & $\begin{array}{l}\text { Study type: any study not assessing involvement with } \\
\text { GA. (e.g., other types of support group for those } \\
\text { with gambling disorder or other twelve-step } \\
\text { programmes that were not specifically GA). }\end{array}$ \\
\hline $\begin{array}{l}\text { Intervention type: Gamblers Anonymous. Largely this } \\
\text { means attendance at GA groups but GA also has a } \\
\text { website which is widely used and any studies which } \\
\text { looked at this were also included. }\end{array}$ & $\begin{array}{l}\text { Nature of the reference: policy papers, theoretical } \\
\text { papers, and commentaries. }\end{array}$ \\
\hline $\begin{array}{l}\text { Outcome: any reference to demographics in terms of } \\
\text { numbers of women attending and any discussion of } \\
\text { the experiences of women in GA. }\end{array}$ & Studies which make no reference to gender. \\
\hline Language: only English-speaking languages. & Language: non-English-speaking papers. \\
\hline
\end{tabular}


A second stage involved searching the websites of relevant international gambling research centres and groups for relevant papers and information. These included The Australian Gambling Research Centre, The Gambling Research Exchange, Ontario (Canada), The Alberta Gambling Research Institute (Canada), The Gambling Research Group (University of Glasgow), and The Gambling and Addictions Research Centre (Auckland University of Technology, New Zealand). Two further studies were identified at this stage. A third stage of the search strategy involved hand searching of the references and bibliographies of studies located during the first two stages. This resulted in four further studies being identified. In sum, these three stages resulted in a total of 192 studies being identified.

Figure 1 provides a flowchart to illustrate the stages of the search strategy and results.

Table 2 summarises the details of the design features, locations, and sample sizes involved in each of the included studies.

\section{Ethics}

Since the study was a review of previously published literature, no specific ethical approval was sought directly for the study.

\section{Results}

\section{Aim One: Determining the Level of Participation of Women in GA}

Four studies were identified that report on the number and proportion of women attending specific GA groups. The first empirical study was conducted in the UK (Turner and Saunders 1990). The authors observed two GA groups in Wales over a period of a year, and noted that most attenders were men-38 out of 41 (93\%). More recently, Ferentzy and colleagues have published perhaps the most detailed studies of GA, in a series of papers based on studies with Canadian groups (Ferentzy, Skinner, and Antze 2006, 2009, 2010). In a paper which discussed changes to the way in which GA operates, they suggest that a key change in the GA dynamic is an increasing proportion of women attenders, noting that it had moved to a level of around $20 \%$ in the Toronto area (Ferentzy, Skinner, Antze 2009). More recently, Venuleo and Marinaci (2017) reported just one woman within sample of 25 GA attenders in Italy (4\%), and Rogers (2018) observed that 28 of 278 separate attendances at a series of GA meetings were by women (10\%), although the majority of these were supporters of men who were also attending the same meetings.

Several other studies, whilst not looking at GA per se, recruited participants from GA for investigation of specific gambling issues and reported on the respective numbers of men and women. The proportion of women in the GA samples in those studies ranged from $4 \%$ (Venuleo and Marinaci 2017) to 42\% (McGrath et al. 2018). In sum, the data suggests that the proportion of those attending GA who are women varies significantly across studies.

\section{Aim Two: To Determine Key Barriers and Facilitators to the Participation of Women}

\section{Barriers}

The most commonly reported barrier for women seems to be an unwelcoming attitude experienced in largely male GA groups. Some of the included studies report conflicting 


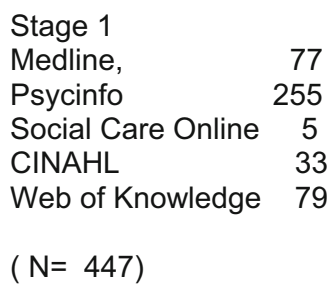

Stage 1

Medline,

Psycinfo

Social Care Online

CINAHL

Web of Knowledge 79

$(\mathrm{N}=447)$

255

5

33

No reference to gender

$$
(n=37)
$$

No reference to $G A$

$(n=20)$
Papers excluded, with reasons.

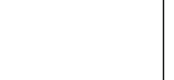

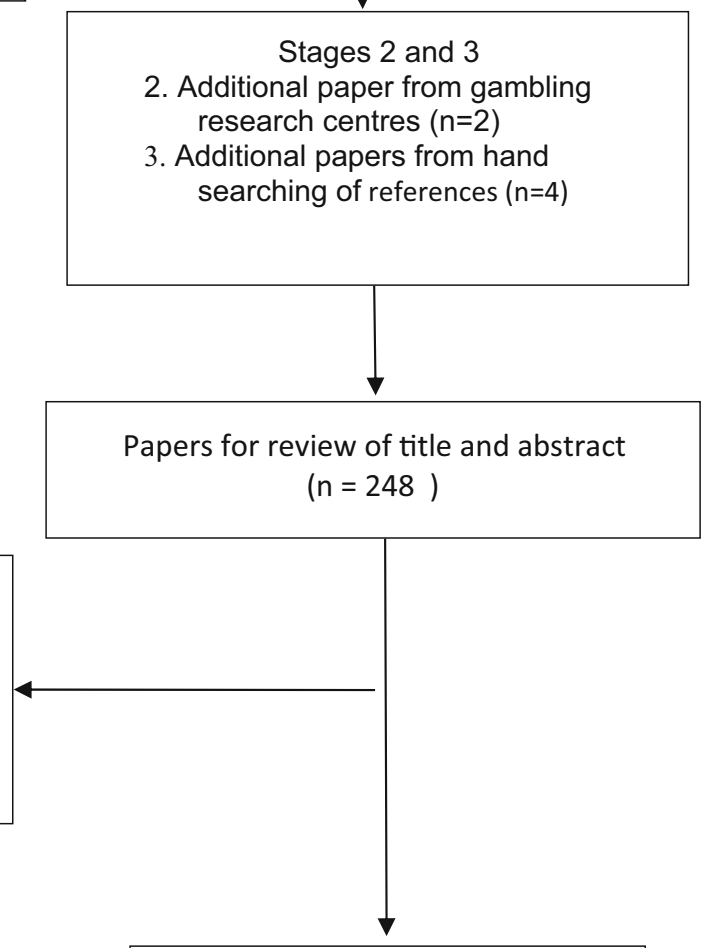

Papers excluded, with reasons.

Inclusion criteria not met

( $n=163$ )

Foreign language and full

translation not available $(n=4)$
Papers for review of full text

$$
(n=192)
$$

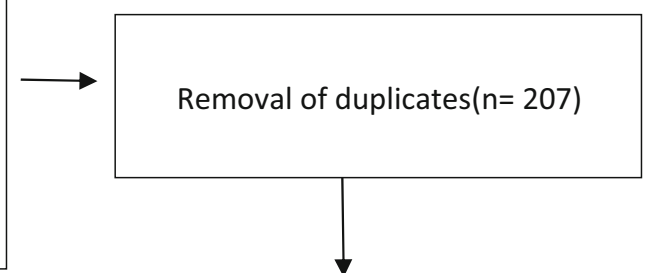

. Additional paper from gambling $n=2)$

dditional papers from hand
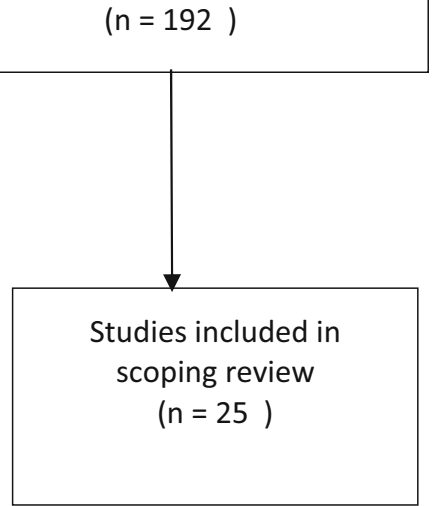

Fig. 1 Flowchart for scoping review. Involvement of women in GA 


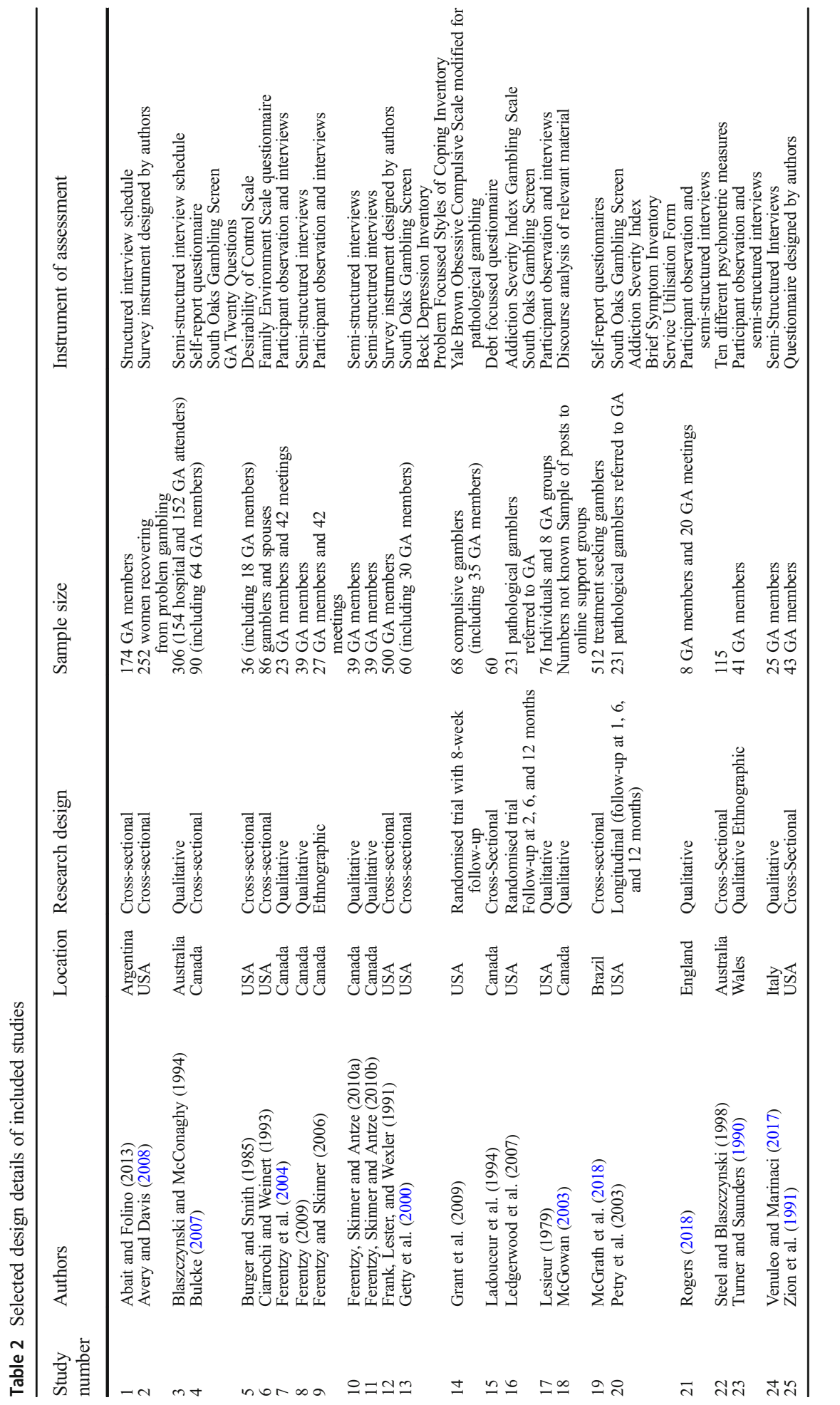


experiences, with a number confirming this male bias (Ferentzy et al. 2006a) whilst others report many women finding GA to be welcoming and supportive (Avery and Davis 2008). Such a finding may reflect the heterogeneity of groups, though some authors suggest that the differences reflect changing cultural expectations over time in terms of gender (Ferentzy et al. 2010a).

Ferentzy et al. (2006a, 2006b) conducted qualitative research with GA members and noted that numerous male members saw gender as irrelevant to gambling problems, whilst females saw the issue as highly pertinent. Some female members of GA complained of a 'boys club' atmosphere and a propensity for men to retell 'war stories' based on their gambling experiences (e.g. dramatic narratives of the worst aspects of their addictive behaviour and the associated consequences), rather than to focus on emotions or positive plans for the future, the latter which women prefer to do according to the authors of that study (Ferentzy et al. 2006a, p69).

Barriers to participation may be related to the differing needs of men and women in terms of both their perceived problems and the type of support that they find useful. Included studies show that women who attend GA are more likely to have co-morbidities in terms of mental health problems (Getty et al. 2000). A pragmatic focus on current issues and a reluctance to explore emotions and relationships have been reported in many of the studies of GA (Ferentzy and Skinner 2003). Such a focus may also explain why women often report that GA is not particularly helpful for them, since it is evident that women who are disordered gamblers usually show a clear preference for help and support which focusses on emotional problems and interpersonal relationships (Hraba and Lee 1996; Crisp et al. 2000).

Rossol (2001) described 38 interviews conducted with GA members in the USA. The study sample included seven females interviewed by telephone and four in person. The author used insights from the sociology of deviance and labelling theory to assess experiences within GA (Rossol 2001). Despite some detailed analysis of these experiences in general terms, there is no analysis of gender and, in the published paper, just one brief account reported by an identified female. The account is nevertheless revealing, as it illustrates key points about the GA philosophy. The female participant recalled exploring why she had started gambling, stating that she had 'an unhappy marriage, sheer curiosity, and too much time on her hands' (p329). When the other members of the GA group were asked by the chair to respond, and if her accounts of reasons for gambling were helpful, the group unanimously said that they were not, with one respondent saying 'you have got to let go of that: you are here now' (p329). The GA philosophy discourages a search for reasons behind why a person gambled, and apply a very pragmatic focus on current gambling issues and a reluctance to focus on what might be seen as mental health or psychological issues. Such an issue may also be because the typical chair of a meeting feels unqualified to deal with such issues (Rogers 2018).

Another study looked specifically at barriers to treatment identified by women involved with GA or other types of problem gambling treatment. Bulcke (2007) recruited 90 Canadian women almost all of whom met criteria for probable pathological gambling using the South Oaks Gambling Screen (SOGS). Ninety-one percent of this sample (82 individuals) had sought help from GA. In this study, the most frequently cited barriers to seeking treatment were reported as 'feeling ashamed to admit I have a gambling problem' as well as 'gambling to deal with the stress of my daily life' in both the GA and non-GA groups.

Individual responses also suggested that the failure of other agencies to refer to GA can be a barrier. Indeed, $47 \%$ of women in this study reported that not knowing what help is available was the major 'programmatic' barrier to treatment (Bulcke 2007, p86). 
In another study, McGowan (2003) reported on an online gender-specific support group which was set up by two women GA members. Accounts describe the gendered nature of experience at GA, with female gambling experiences being ridiculed or belittled. For example, 'you (female) have not lost enough..... any monkey can pull a handle... you are not a gambler honey' (p123). One observer noted that 'many women felt uncomfortable at men dominated meetings with no-one they could readily relate to - uncomfortable with the aggressive approach from many men in the program. Many .....reported feeling that the meetings were too loud, aggressive, demanding, and full of put downs. They felt more stress, not less, after a meeting' (p123). The author suggested that the online group provided a space in which women's gendered experiences are acknowledged and their resistance to misogyny made public. 'For the women who participate, the newsgroup provides a forum where stories emerge that resist the hegemonic master narratives or dominant social ideologies and men-dominated GA groups' (McGowan 2003, p128).

A more recent qualitative study by Kaufman et al. (2017) explicitly set out to use in-depth interviews with eight female participants to examine barriers to help seeking for women with gambling problems in the UK. The participants were recruited from women who had completed treatment involving CBT at the National Problem Gambling Clinic. Accounts were given by some women who had previously felt explicitly rejected by a GA meeting. One participant confirmed the same misconception that men attend GA and women only go to meetings as partners and supporters. In an earlier study, Cooper (2004) noted that the only difference between men and women in terms of reported barriers to help seeking for problem gambling was that women avoided GA because it was inconvenient, generally meaning that there was no GA meeting in their home town. These studies suggest that if GA is geographically accessible to a woman and she does not have a bad initial experience in terms of being rejected by men at the group, then GA can provide a very useful source of help.

\section{Facilitators}

Several of the included studies suggest that the most frequently referenced facilitator to participation in GA seems to be the participation of a spouse or other supporter in the partner organisation GamAnon. GamAnon is a partner organisation of GA, set up to provide help to partners and others affected by the actions of a disordered gambler (GamAnon 2005).

In a study observing of GA in South Wales, UK, in the 1980s, Turner and Saunders (1990) observed that 'What did become evident was that the attendances of GA members were highly dependent upon the commitment and even the attendance of Gam Anon members' (p3). Such a finding was echoed by Ferentzy and colleagues who have conducted a number of studies with GA groups in Canada. However, as they noted, GA members remained almost exclusively male, and most of the supporters are female (Ferentzy and Skinner 2003, 2004).

In a subsequent study, Ferentzy et al. (2010a) posited that the role of women in both GA and the partner organisation Gam Anon has rapidly changed. The authors noted that more female partners of male problem gamblers were choosing to leave their partners, changing the traditional dynamic in which the male gambler attended GA and the dutiful female companion stuck by their man and provided emotional and programme support (Ferentzy et al. 2010a). Such a study also highlighted the historical importance of women to male GA members, usually via their role in attending Gam Anon and supporting their partners in maintaining abstinence and attendance at meetings. "In short, loyal women have been integral to recovery in GA, and to a far greater extent than has been the case in similar mutual aid societies" 
(Ferentzy et al. 2010a, p488). Moreover, the authors suggested that, for the set up in North America at least, one cannot understand GA without a serious consideration of GamAnon's role. Such a premise is based on evidence from a range of groups across Canada and the USA, but with relatively small numbers overall: 26 men and 13 women (33\%) (Ferentzy et al. 2010a). Given such small numbers, it is difficult to draw firm conclusions from these findings but the similarity with the findings from Turner and Saunders (1990) suggests that they may be generalisable.

The above finding suggests that for women who are partners/supporters of a male disordered gambler, guidance is given which signposts them towards the support provided by GamAnon. For women who are disordered gamblers themselves, the picture is somewhat different. As noted in the section above regarding participation levels, relatively few female gamblers attend GA, and few have spouses/supporters attending GamAnon. Avery and Davis (2008) found that, where a woman was attending GA for help with her own gambling problem, only $8 \%$ reported having a relative or friend attending Gam Anon.

For women who do attend GA, this appears to be facilitated by referrals and encouragement from friends and family, but also from professionals and publicly available information. For example, Avery and Davis (2008) note that many of those who attended GA were referred via a free telephone helpline (38\%) followed by referrals by professional counsellors (32\%) and yellow pages (18\%).

As noted above, the failure to refer has been established as a barrier to participation in some studies. Once they do attend GA, the evidence seems to suggest that whilst some groups are male dominated and unwelcoming, this is not always the case. Avery and Davis (2008) reported that the majority of women felt welcomed and understood at GA; such a supposition supports the more recent findings of Ferentzy et al. (2006b), but contrasts with the arguments put forward by McGowan (2003) and Kaufman (2017). Specifically, over a third of females (37\%) valued being received and understood by others with a similar problem and over a third (36\%) referred to friendly behaviour and personal attention at the meetings. Some women admitted to feeling unwelcome at first but then very much part of the group as regular attendance developed (Avery and Davis 2008).

Ferentzy et al. (2006a) noted the changing nature of GA. They suggest that GA has taken steps to make meetings more welcoming to women. Such steps include welcoming discussion of emotional and life issues, where such discussions were once suppressed, and being far less confrontational in terms of how conversations in group meetings proceed. The authors suggest that, once women become involved, there is evidence that they help generate a more nurturing atmosphere in GA meetings with more focus on emotional responses. Such a change may then encourage more women to attend, and also change the nature of men's participation, as the following statement suggests:

'As the women came in and they brought a sense of sensitivity to the rooms-there's some guys that were sensitive, and this allowed them to come out a little bit more, you know?' (Ferentzy et al. 2006a, p70). For those women who overcome barriers to involvement, many find the sharing and the support from others with similar problems to be an important facilitator of recovery and of continuing involvement in what becomes an important social support and even friendship group. Bulcke (2007) reported many instances of this nature, such as the following.

I find GA group therapy very rewarding and helpful. Everyone is not judgemental or accusing, questioning - the key word here is understanding and great support... I have nothing but praise for the program (p187). 
More than a support system- it's a very close group of friends who share the same illness as I do. Some friendships are the closest that I've ever shared in my life (we laugh, we cry, we celebrate and we support one another in times of sadness and joy) (p187)

Given the male dominance of some GA meetings and the experience of being out of place or unwelcome by some females, one facilitator of women's involvement may be to move towards women-only meetings which offer a distinct experience. As discussed earlier, women are more likely to present with other co-morbid problems alongside the gambling such as anxiety, depression, or mood disorders (Wenzel and Dahl 2009), and substance-use disorders (Blanco et al. 2006; Grant and Kim 2002; Petry et al. 2005). It is perhaps not surprising that, as some suggest, women are more likely to welcome opportunities to discuss a range of issues, rather than just the addiction in question, when in any treatment programme (Lesieur 1988).

The twelve-step fellowships have few rules. The only requirement for membership of GA is a desire to stop gambling. Because of this, it is not permitted to have single-sex (i.e. womenonly) meetings. However, in 1992, a GA meeting was established in Arizona by a woman who advertised it with the suggestion - 'women preferred'. The idea spread, and men were politely asked to find alternative meetings, rendering these meetings effectively women only. As noted by the woman who developed the first of these, 'there are issues that women cannot talk about in front of men, very personal, like maybe child abuse or sexual abuse or physical abuse by a husband or another man' (Davis 2009, p.101).

These 'women-preferred' meetings have expanded to the UK and elsewhere.

McGowan (2003) observed the number of women who, when asked about their experiences at GA, described the intentional pursuit of or the development of women-only groups. Other studies have suggested that women who attend GA establish informal networks with other women in the mutual support group and also maintain these relationships outside the GA environment (Laracy 2011).

Involvement can also be facilitated by pragmatic considerations such as venue and timing. GA meetings are almost always evening based, but some women-only groups have been run in the daytime, because this was the time when many women gambled, and also fitted better with childcare responsibilities (McGowan 2003).

Barriers to participation can be summarised in terms of 'external' barriers such as lack of referral and signposting, lack of accessible meetings, and costs of travel, and 'internal' barriers such as shame, stigma, and fear of disclosure, alongside features of the GA meetings and discourse, such as a climate which is dismissive of women's experiences. A male-dominated environment which is perceived as hostile or unwelcoming may remain a significant barrier to the involvement of women.

Facilitators can be summarised as getting a direct referral from a professional, the encouragement of friends and family, and finding a group which is welcoming of women.

\section{Discussion}

In relation to the first aim of this review, determining levels of participation, very few studies looked directly at the proportion of women attending specific GA groups. Those that did show heterogeneity, with a range from 4 to $25 \%$, allowing few conclusions to be drawn. Some studies used GA only as a control arm in treatment studies looking at other interventions. Results from these at least give some data about proportions of women in various GA groups 
in North America and the UK. Almost all of the relevant studies which have been conducted took place in these countries and there remains a gap in the literature in relation to studies in the many other countries in which GA groups take place.

If we view these numbers in relation to the gender balance in the statistics recorded by other agencies offering help to disordered gamblers, they remain lower than for most other forms of gambling treatment. For the main funded treatment provider in the UK, GamCare, some 15\% of almost 25,000 gamblers who sought help from their telephone helpline in 2016/2017 were female, and $13 \%$ of those accessing counselling from that organisation (GamCare 2017). In North America, proportions using other forms of help seem to be consistently higher than for GA. Potenza et al. (2001) reported that $37 \%$ of callers to a helpline in a US state were female and Heater and Paton (2006) reported $43 \%$ in relation to a Canadian helpline. Other parts of the world also report a more even gender balance with studies from New Zealand (Tan and Wurtzburg 2004) and Australia (Delfabbro 2009) reporting that 50\% of those seeking help are women. The exact reasons for these national differences remain unknown but may reflect a wide range of features relating to cultural differences and differences in the way that treatment services are organised and advertised.

The relatively low proportion of GA attenders who are women suggests that there are some particular barriers which prevent them from accessing this form of help. From our review, barriers to participation for women can best be summarised in terms of 'external' barriers such as lack of referral and signposting, lack of accessible meetings, and costs of travel alongside 'internal' barriers such as shame, stigma, fear of disclosure, and features of the GA meetings and discourse, such as a climate which is dismissive of women's experiences. The latter point could be classed as 'issues with treatment itself' and this was also one of four types of barrier highlighted by Suurvali et al. (2009), in a non-gender specific review of barriers to accessing treatment for problem gambling (the other three were wish to handle the problem by oneself, shame/embarrassment/stigma, and unwillingness to admit the problem).

Issues relating to shame and stigma seem to be particularly problematic in the context of women and help seeking for gambling problems, and have been highlighted in a number of studies. Some suggest that individual factors, particularly shame and depression provide almost all of the reported barriers to help seeking in the case of women (Boughton and Brewster 2002; Bulcke 2007). Other researchers suggest that a sense of shame and stigma is a common feeling among problem gamblers and is particularly strong in women (Pulford et al. 2009, Hing et al. 2014) which leads to a reluctance to seek help, or to share the problem. Hing et al. (2015) have shown how shame prevents many women with gambling problems from taking advantage of self-exclusion programmes which are available to them. In this review, a number of the included studies found that the same issues prevent women attending GA (Bulcke 2007; Cooper 2003; Kaufman et al. 2017).

On the positive side, Baxter et al. (2016) explored in detail gendered differences in relation to stigma. They showed that the nature of felt stigma is somewhat different for women, and that the aspects of gambling which were more likely to cause stigma for them in relation to help seeking related to 'being seduced by the 'bells and whistles' of the gambling venue, their denial of their addiction, their belief in luck and that the casino can be beat, and the shame of being dishonest' (p1). Noting the educational role of the meetings, they suggested that GA can help people to overcome felt stigma and to seek treatment. The authors suggest that the type of peer support that GA offers may be particularly useful as people with lived experience may be more able to break through barriers of shame and stigma to make a connection with problem gamblers. 
However, a male-dominated environment which is perceived as hostile or unwelcoming may remain a significant barrier to the involvement of women, even if they make a first contact with the organisation. Authors of some of the more detailed studies (e.g. Ferentzy et al. 2010a; Avery and Davis 2008) suggest that there has been a significant change over time in terms of the experiences of women. Reassuringly, GA is becoming a more welcoming space for women, and one which they are utilising and finding helpful more often. Ferentzy et al. (2010a) were very clear about this change in Canada, suggesting that traditional gender roles were rapidly changing. However, studies by Ferentzy and Skinner (2003, 2006b), McGowan (2003) and a more recent study by Kaufman et al. (2017) find that some women perceive that there is still a somewhat hostile atmosphere for women. Such a finding probably reflects heterogeneity in terms of individual GA groups within countries, but also cross national differences in how GA operates and points to the need for further studies which capture the experiences of people across a range of GA groups in different countries.

The present review shows that 'issues with treatment itself' (e.g. the perception that the group is not welcoming or not suitable to meet the individual's needs) may be problematic in relation to some but by no means all GA groups. Also, the lack of signposting and referral may interact with issues of shame, stigma, and a wish to handle the problem alone with the result that the majority of women problem gamblers do not seek or find this form of help. Where GA can provide local, accessible, and timely help, it seems warranted to recommend that individuals and agencies make greater efforts to signpost and refer women to local GA meetings.

A number of the included studies observed or investigated co-morbidities and links between gambling and mental illness. Studies have consistently suggested that many people classified as problem or pathological gamblers have co-occurring problems, with $57 \%$ having a substance misuse disorder and 38\% a mood disorder (Lorains et al. 2011; Najavits et al. 2011). Data show that this remains a particular issue for women (Getty et al. 2000). GA may then be a more useful ally to women if it includes or is aligned to something which is not solely focussed on gambling. As Schuler et al. (2016) noted in their review of GA, 'it is also possible that single focus mutual aid fellowships such as GA may often be ineffective because of the complex needs of many members of this population' (p1274). Some authors have pointed to the improved outcomes for those with co-morbidities when they attend dual focus groups (Rosenblum et al. 2014). A practical problem with that is that there are not always enough accessible GA groups and dual focus groups are, in comparison, quite rare.

Women-only GA groups have been established in a number of locations and were discussed in some studies in this review. However, it cannot be assumed that women necessarily demand women-only spaces. For some, this is a welcome development, particularly for the discussion of personal issues. However, other studies have found that women with co-morbidities such as Post Traumatic Stress Disorder (PTSD) and substance abuse did not prefer women-only twelve-step groups. Participants in one study suggested that the focus on managing PTSD was far more important than any gender-related issue (Najavits et al. 2015).

An alternative option is to set up women-only spaces online. Studies included in this review by Bulcke (2007) and McGowan (2003) detail the benefits of this approach. There are a range of options for online support in relation to disordered gambling. In these examples, support groups following the GA model were the focus. In a number of countries, GA also has its own website, which includes discussion forums and other options for interaction. For example, in the UK, the GA website is well used, and has several thousand posts which are viewed over 20,000 times per year (Rogers 2018). Online support may be useful in overcoming the barriers to the involvement highlighted above, including male-dominated and unwelcoming face-to- 
face meetings, problems with accessing meetings, and also issues of shame and stigma, since a person can remain anonymous during online interaction. In fact, in recent years (2015), the UK-based Gordon Moody Association (GMA) have launched a mainly online treatment programme for women disordered gamblers which has proved to be a great success. GMA provide advice, education therapeutic support to problem gamblers and those affected by problem gambling, through residential, online, and outreach services (see Roberts et al. 2017).

In the digital age, technology-based support is often offered as an adjunct to other forms of support as well as separately. For those attending GA, peer text messaging has been shown to be a helpful source of support and encouragement between meetings (Rogers 2018). Likewise, Rodda et al. (2018) found that text messages were as helpful as other forms of support in leading to a reduction in gambling related symptoms and in time and money spent gambling.

Some of the included studies suggest that where women do overcome the barriers and begin a relationship with GA, whether at face-to-face groups or online, they tend to do so more intensively and frequently. Evidence has shown that more intensive and frequent involvement is correlated with better outcomes (Schuler et al. 2016). Such a finding corresponds with a recent scoping review of self-help groups for alcohol dependency. The review found that levels of attendance and involvement at Alcoholics Anonymous (AA), and having a conveniently located AA group, were key factors linked to positive outcomes and abstinence (Parkman, Lloyd, and Spilsbury 2015).

This review has a number of limitations. Whilst every attempt was made to conduct a comprehensive review, some relevant material may well have been overlooked. Resources were not available for translation and some non-English language published studies were found in the initial search which could not be included. This review intentionally looked only at GA and did not look at other forms of self or mutual help for women recovering from disordered gambling. It is known that non-twelve-step group programmes have been proven to produce favourable outcomes in relation to addictions (Parkman et al. 2015). GA remains a significant source of help and the aim was to find out more about this under researched community. However, it would be informative to collate information on the many other forms of help offered to women with gambling problems.

Whilst a reasonable number of qualitative studies were found, most were based on data from self-report, questionnaires, and semi-structured interviews. Moreover, many of these studies were conducted more than 10 years ago. It is evident that studies are needed which obtain information from directly 'inside' GA to elucidate more about the nature of experiences and processes which take place there. The name and nature of 'anonymous' programmes will always provide a challenge for researchers wishing to study them. Options include participant observation studies and contacts at conferences or conventions where a large numbers of individuals may by surveyed at one time (Zion et al. 1991; Lorenz and Yaffee 1988).

\section{Conclusion}

Little is known about the intricacies of GA and even less about the experiences of women in that community, though they represent a growing proportion of the population with gambling problems and a growing proportion of the attenders at GA. This paper brings together and summarises what is known about the issue. In situating this knowledge within a broader literature of help seeking in relation to addictive behaviour, this paper contributes to knowledge about what is common in relation to that help seeking, what is specific to Gamblers 
Anonymous, and what is specific to the experiences of women. Bringing together such information is a substantial step towards informing treatment practice, and also an important one in highlighting the most pressing questions and gaps in knowledge which remain.

In some countries, including the UK, GA provides a significant proportion of the help that is essentially available to problem gamblers (Rogers 2018). As the proportion of problem gamblers who are women is increasing, GA should occupy a greater focus in research strategies, and gendered analyses should be part of any such research.

\section{Compliance with Ethical Standards}

Conflict of Interest The authors declare that they have no conflict of interest.

Open Access This article is distributed under the terms of the Creative Commons Attribution 4.0 International License (http://creativecommons.org/licenses/by/4.0/), which permits unrestricted use, distribution, and reproduction in any medium, provided you give appropriate credit to the original author(s) and the source, provide a link to the Creative Commons license, and indicate if changes were made.

\section{References}

Abait, P., \& Folino, J. (2013). Pathological gambling, illegal behavior and the preventive potentiality of a helpline in Argentina. Vertex, 24(108), 85-91.

Abbott, N., Volberg, R., Bellringer, M., \& Reith, G. (2004). A review of aspects of problem gambling. Final report. Auckland: Auckland University of Technology.

Abbott, M. W., Romild, U., \& Volberg, R. A. (2014). Gambling and problem gambling in Sweden: changes between 1998 and 2009. Journal of Gambling Studies, 30, 985-999.

Afifi, T. O., Brownridge, D. A., MacMillan, H., \& Sareen, J. (2010). The relationship of gambling to intimate partner violence and child maltreatment in a nationally representative sample. Journal of Psychiatric Research, 44, 331-337.

American Psychiatric Association. (2013). Diagnostic and statistical manual of mental disorders (5th ed.). Arlington: American Psychiatric Publishing.

Arksey, H., \& O'malley, L. (2005). Scoping studies: towards a methodological framework. International Journal of Social Research Methodology, 8(1), 19-32.

Avery, L., \& Davis, D. (2008). Women's recovery from compulsive gambling: formal and informal supports. Journal of Social Work Practice in the Addictions, 8(2), 171-191.

Baxter, A., Baxter Salmon, C., Dufresne, K., Carasco-Lee, A., \& Matheson, F. (2016). Gender differences in felt stigma and barriers to help-seeking for problem gambling. Addictive Behaviors Reports, 3, 1-8.

Blanco, C., Hasin, D. S., Petry, N., Stinson, F. S., \& Grant, B. F. (2006). Sex differences in subclinical and DSMIV pathological gambling: results from the National Epidemiologic Survey on Alcohol and Related Conditions. Psychological Medicine, 36, 943-953.

Boughton, R., \& Brewster, J. (2002). Voices of women who gamble in Ontario: a survey of women's gambling, barriers to treatment and treatment service needs. Toronto: Ministry of Health and Long-Term Care.

Bowden-Jones, H., \& Prever, F. (2017). Gambling Disorders in Women. London: Routledge, UK.

Bulcke, G. (2007). Identifying barriers to treatment among women gamblers. Pittsburgh: University of Pittsburgh.

Burger, J. M., \& Smith, N. G. (1985). Desire for Control and Gambling Behavior among Problem Gamblers. Personality and Social Psychology Bulletin, 11(2), 145-152.

Centre for Reviews and Dissemination (CRD). (2001). Undertaking systematic reviews of research on effectiveness: CRD's guidance for those carrying out or commissioning reviews CRD Report 4 (2nd ed.). York: NHS Centre for Reviews and Dissemination, University of York.

Ciarrocchi, J. W., \& Reinert, D. F. (1993). Family environment and length of recovery for married male members of Gamblers Anonymous and female members of GamAnon. Journal of Gambling Studies, 9, 341-352.

Conolly, A., Davies, B., Fuller, E., Heinze, N., \& Wardle, H. (2018). Gambling behaviour in Great Britain 2016. Evidence from England, Scotland and Wales. London: Nat Cen Social Research.

Cooper, G. (2003). Exploring and understanding online assistance for problem gamblers: The pathways disclosure model. eCommunity: International Journal of Mental Health \& Addiction, 1(2), 32-38. 
Cooper, G. (2004). Exploring and understanding online assistance for problem gamblers: the pathway disclosure model. Int J Ment Heal Addict, 1, 32-38.

Crisp, B. R., Thomas, S. A., Jackson, A. C., Thomason, N., Smith, S., \& Borrell, J. (2000). Sex differences in the treatment needs and outcomes of problem gamblers. Research on Social Work Practice, 10(2), 229-242.

Crisp, B., Thomas, S., Jackson, A., Smith, S., Borrell, J., Ho, W., Holt, T., \& Thompson, N. (2004). Not the same: a comparison of female and male clients seeking treatment from problem gambling counselling services. Journal of Gambling Studies, 20(3), 283-299.

Davis, D. (2009). Taking back your life. Women and problem gambling. Minnesota: Hazelden.

Delfabbro, P.H. (2009). Australasian gambling review (1992-2008), 4th ed. S. Aust.: Independent Gambling Authority. 2012

Ferentzy, P., \& Skinner, W. (2003). Gamblers Anonymous. A critical review of the literature. Egambling the Electronic Journal of Gambling Issues, 9, 1-29.

Ferentzy, P., Skinner, W., \& Antze, P. (2004). Gender differences in Gamblers Anonymous. International Journal of Self Help and Self Care, 2(4), 271-280.

Ferentzy, P., Skinner, W., \& Antze, P. (2006a). Rediscovering the 12 steps: recent changes in Gamblers Anonymous. Journal of Groups in Addiction and Recovery, 1(3/4), 59-74.

Ferentzy, P., Skinner, W. and Antze, P. (2006b). Recovery in gamblers anonymous. Journal of Gambling Issues, 17.

Ferentzy, P., Skinner, W.,\& Antze, P. (2009). Gamblers anonymous and the 12 steps: How an informal society has altered a recovery process in accordance with the special needs of problem gamblers. Journal of Gambling Issues, 23. https://doi.org/10.4309/jgi.2009.23.3.

Ferentzy, P., Skinner, W., \& Antze, P. (2010a). Changing spousal roles and their effect on recovery in gamblers anonymous: GamAnon, social support, wives and husbands. Journal of Gambling Studies, 26(3), 487-501.

Ferentzy, P., Skinner, W., \& Antze, P. (2010b). The serenity prayer: Secularism and spirituality in gamblers anonymous. Journal of Groups in Addiction \& Recovery, 5(2), 124-144.

Frank, M., Lester, D., \& Wexler, A. (1991). Suicidal behavior among members of Gamblers Anonymous. Journal of Gambling Studies, 7, 249-254. https://doi.org/10.1007/BF01019876.

GamAnon. (2005). The Gam-Anon way of life. New York: GamAnon.

Gamblers Anonymous. (2017). Meeting finder. Retrieved from https://www.gamblersanonymous.org.uk/index. php/meetings. Accessed 23 Feb 2019.

Gambling Commission. (2018). Review of online gambling. London: Gambling Commission.

GamCare. (2017). Annual statistics 2017. London: GamCare.

Getty, H. A., Watson, J., \& Frisch, G. R. (2000). A comparison of depression and styles of coping in male and female GA members and controls. Journal of Gambling Studies, 16(4), 377-391.

Grant, J. E., \& Kim, S. W. (2002). Gender differences in pathological gamblers seeking medication treatment. Comprehensive Psychiatry, 43, 56-62.

Grant, J. E., Donahue, C. B., Odlaug, B. L., Kim, S. W., Miller, M. J., \& Petry, N. M. (2009). Imaginal desensitisation plus motivational interviewing for pathological gambling: randomised controlled trial. British Journal of Psychiatry, 195(3), 266-267.

Griffiths, M. (1999). Gambling technologies: prospects for problem gambling. Journal of Gambling Studies, 15(3), 265-283.

Griffiths, M. (2014). Problem gambling in Great Britain. A brief review. Report prepared for the association of British Bookmakers. http://abb.uk.com/wp-content/uploads/2014/09/Problem-Gambling-in-Great-BritainABrief-Review.pdf. Accessed 6 June 2018.

Heater, J. \& Paton, D. (2006). Gender differences in problem gambling behaviour from help-line callers. Journal of Gambling Studies, 6. DOI: https://doi.org/10.4309/jgi.2006.16.21.

Hing, N., Holdsworth, L., Tiyce, M., \& Breen, H. (2014). Stigma and problem gambling: current knowledge and future research directions. International Gambling Studies, 14(1), 64-81. https://doi.org/10.1080 /14459795.2013.841722.

Hing, N., Nuske, E., Gainsbury, S., \& Russell, A. (2015). Perceived stigma and self-stigma of problem gambling: perspectives of people with gambling problems. International Gambling Studies, 16(1), 31-48.

Hraba, J., \& Lee, G. (1996). Gender, gambling and problem gambling. Journal of Gambling Studies, 12(1), 83-101.

Kaufman, A., Jones Nielson, J., \& Bowden-Jones, H. (2017). Barriers to treatment for female problem gamblers: a UK perspective. Journal of Gambling Studies, 33(3), 975-991.

Kelly, J. (2017). Is Alcoholics Anonymous religious, spiritual, neither? Findings from 25 years of mechanisms of behaviour change. Addiction, 112(6), 929-936.

Lesieur, H. R. (1988). The female pathological gambler. In W. R. Eadington (Ed.), Gambling research: Proceedings of the Seventh International Conference on Gambling and Risk Taking (Vol. 5, pp. 230-258). Reno: University of Nevada. 
Ladouceur, R., Boisvert, J. M., Pépin, M., Loranger, M., \& Sylvain, C. (1994). Social cost of pathological gambling. Journal of Gambling Studies, 10(4), 399-409.

Laracy, A. J. (2011). The promise of another spin: Identity and stigma among video lottery players in St. John's, Newfoundland and Labrador, (AAIMR88011). Newfoundland:Memorial University of Newfoundland.

Ledgerwood, D. M., Weinstock, J., Morasco, B. J., \& Petry, N. M. (2007). Clinical features and treatment prognosis of pathological gamblers with and without recent gambling-related illegal behavior. Journal of the American Academy of Psychiatry \& the Law, 35(3), 294-301.

Lesieur, H. (1979). The Compulsive Gambler's Spiral of Options and Involvement. Psychiatry Interpersonal and Biological Processes, 42(1), 79-87.

Lorains, F., Cowlishaw, S., \& Thomas, S. (2011). Prevalence of comorbid disorders in problem and pathological gambling: systematic review and meta-analysis of population surveys. Addiction, 106(3), 490-498. https://doi.org/10.1111/j.1360-0443.2010.03300.x.

Lorenz, V. C., \& Yaffee, R. A. (1988). Pathological gambling, psychosomatic, emotional and mental differences as reported by the spouse of the gambler. Journal of Gambling Behavior, 4(1), 13-26.

McGowan, V. (2003). Counter-story, resistance and reconciliation in online narratives of women in recovery from problem gambling. International Gambling Studies, 3(2), 115-131.

McGrath, D., Kim, H., Hodgins, D., Novitsky, C., \& Tavares, H. (2018). Who are the anonymous? Involvement and predictors of Gamblers Anonymous attendance among disordered gamblers presenting for treatment. Journal of Gambling Studies, 34, 1423-1434. https://doi.org/10.1007/s10899-018-9774-y.

Najavits, N., Meyer, T., Johnson, K., \& Korn, D. (2011). Pathological gambling and posttraumatic stress disorder: A study of the co-morbidity versus each alone. Journal of Gambling Studies, 27, 663-683.

Najavits, L., de Haan, H., \& Kok, T. (2015). How do females with PTSD and substance abuse view 12-step groups? An empirical study of attitudes and attendance patterns. Substance Use and Misuse, 50(14), 1786-1794.

Parkman, T. J., Lloyd, C., \& Spilsbury, K. (2015). Self-help groups for alcohol dependency: A scoping review. Journal of Groups in Addiction \& Recovery, 10(2), 102-124. https://doi.org/10.1080/1556035 X.2015.1034824.

Petry, N. M. (2003). Patterns and correlates of gamblers anonymous attendance in pathological gamblers seeking professional treatment. Addictive Behaviors, 28(6), 1049-1062.

Petry, N. M., \& Steinberg, K. L. (2005). Childhood maltreatment in male and female treatment-seeking pathological gamblers. Psychology of Addictive Behaviors, 19, 226-229.

Petry, N. M., Stinson, F. S., \& Grant, B. F. (2005). Comorbidity of DSM-IV pathological gambling and other psychiatric disorders: results from the national epidemiologic survey on alcohol and related conditions. Journal of Clinical Psychiatry, 66, 564-574.

Potenza, M. N., Steinberg, M. A., McLaughlin, S. D., Wu, R., Rounsaville, B. J., \& O’Malley, S. S. (2001). Gender-related differences in the characteristics of problem gamblers using a gambling helpline. American Journal of Psychiatry, 158, 1500-1505.

Pulford, J., Bellringer, M., Abbott, M., Clarke, D., Hodgins, D., \& Williams, J. (2009). Barriers to help seeking for a gambling problem: the experiences of gamblers who have sought specialist assistance and the perceptions of those who have not. Journal of Gambling Studies, 25(1), 33-48.

Roberts, A., Champion, R., \& Irving, S. (2017). Women and gambling: a UK perspective. In H. Bowden-Jones \& F. Prever (Eds.), Women and gambling. New York: Springer.

Rodda, S., Dowling, N., Knaebe, B., \& Lubman, D. (2018). Does SMS improve gambling outcomes over and above access to other e-mental health supports? A feasibility study. International Gambling Studies, 18(2), $343-357$.

Rogers, J. (2018). Gamblers Anonymous in the United Kingdom: a qualitative analysis. Alcoholism Treatment Quarterly, 37, 123-146. https://doi.org/10.1080/07347324.2018.1457412.

Rosenblum, A., Matusow, H., Fong, C., Vogel, H., Uttaro, T., Moore, T., \& Magurae, S. (2014). Efficacy of dual focus mutual aid for persons with mental illness and substance misuse. Drug and Alcohol Dependence, 135, $78-87$.

Rossol, J. (2001). The medicalization of deviance as an interactive achievement: the construction of compulsive gambling. Symbolic Interaction, 24(3), 315-341.

Schuler, A., Ferentzy, P., Turner, N., Skinner, W., McIsaac, K., Ziegler, C., \& Matheson, F. (2016). Gamblers Anonymous as a recovery pathway: a scoping review. Journal of Gambling Studies, 32(4), 1261-1278.

Steel, Z., \& Blaszczynski, A. (1998). Impulsivity, personality disorders and pathological gambling severity. Addiction, 93(6), 895-905.

Suurvali, H., Cordingley, J., Hodgins, D. C., \& Cunningham, J. (2009). Barriers to seeking help for gambling problems: a review of the empirical literature. Journal of Gambling Studies, 25(3), 407-424.

Svensson, J., \& Romild, U. (2014). Problem gambling features and gendered gambling domains amongst regular gamblers in a Swedish population-based study. Sex Roles, 70(5-6), 240-254. 
Tan, T., \& Wurtzburg, S. (2004). Problem gambling in New Zealand. Perspectives on treatment. Petone: Steele Roberts.

Turner, D. N., \& Saunders, D. (1990). Medical relabeling in gamblers anonymous: the construction of an ideal member. Small Group Research, 21(1), 59-78.

Venuleo, C., \& Marinaci, T. (2017). The social construction of the pathological gambler's identity and its relationship with social adaptation: narratives from members of Italian Gambling Anonymous and GamAnon family groups. Journal of Gambling Issues, (36), 138-163.

Viets, V. C. L., \& Miller, W. R. (1997). Treatment approaches for pathological gamblers. Clinical Psychology Review, 17(7), 689-702.

Wardle, H., \& Seabury, C. (2013). Gambling behaviour. In R. Craig \& J. Mindell (Eds.), Health survey for England 2012. Leeds: Information Centre for Health and Social Care.

Wardle, H., Moody, A., Spence, S., Orford, J., Volberg, R., Jotangia, D., Griffiths, M., Hussey, D., \& Dobbie, F. (2011). British Gambling Prevalence Survey 2010. Prepared for The Gambling Commission. London: National Centre for Social Research.

Wenzel, H. G., \& Dahl, A. A. (2009). Female pathological gamblers: a critical review of the clinical findings. International Journal of Mental Health and Addiction, 7(1), 190-202.

Zion, M., Tracy, E., \& Abell, N. (1991). Examining the relationship between spousal involvement in Gam Anon and relapse behaviours in pathological gamblers. Journal of Gambling Studies, 7(2), 117-113.

Publisher's Note Springer Nature remains neutral with regard to jurisdictional claims in published maps and institutional affiliations.

\section{Affiliations}

\section{Jim Rogers ${ }^{1} \cdot$ Jason Landon ${ }^{2} \cdot$ Stephen Sharman $^{3} \cdot$ Amanda Roberts $^{4}$}

1 School of Health and Social Care, College of Social Science, University of Lincoln, Brayford Pool, Lincoln, Lincolnshire LN6 7TS, UK

2 Department of Psychology, Gambling and Addictions Research Centre Faculty of Health \& Environmental Sciences, AUT University, 90 Akoranga Drive, Northcote, Auckland 1142, New Zealand

3 School of Psychology, University of East London, Water Lane, London E15 4LZ, UK

4 School of Psychology, College of Social Science, University of Lincoln, Brayford Pool, Lincoln, Lincolnshire LN6 7TS, UK 